\title{
Technological, economic and legislative opportunities and barriers for panel apartment buildings energy efficient reconstruction in Russia
}

\author{
Kseniia Maltceva ${ }^{1, *}$, and Stanislav Pridvizhkin ${ }^{1}$ \\ ${ }^{1}$ URFU, Institute of Civil Engineering and Architecture, 620002 Yekaterinburg, Russia
}

\begin{abstract}
In the middle of the twentieth century there was a need for a significant amount of housing in Russia as soon as possible caused by the necessity to restore buildings destroyed during the war years, as well as rapid urbanization. Panel apartment houses have become an excellent solution to this problem, due to the simplicity and short construction time. However, recently such buildings do not meet the requirements of comfort, safety and economy. Not only Russia, but also the countries of Eastern Europe, Germany and Japan faced this problem at the turn of the century. In this article, analogues of the panel houses renovation with increasing energy efficiency of their thermal envelope in different countries are considered. It is conducted a comprehensive analysis of the existing legislation of the Russian Federation in the field of reconstruction. Technical opportunities to improve the comfort and energy efficiency of panel buildings and their economic advisability were considered by the example of panel apartment building in Ekaterinburg.
\end{abstract}

\section{Introduction}

According to International energy agency energy intensity of Russia's GDP is 11 times higher than in Germany, 6 times higher than in Canada, 4 times higher than in Poland. Therefore, in 2010 the Government adopted the State Program of the Russian Federation "Energy saving and increase of energy efficiency for the period up to 2020" [1]. Due to the implementation of the activities indicated in the Program, the reduction of the energy intensity of Russia's GDP by $13.5 \%$ should be achieved.

As it was calculated by the Russian Federation Ministry of Energy, the potential for energy saving in the housing and utilities sector is about 95-110 million tons of standard fuel. Due to mass urbanization since the beginning of the 1960s, Russian cities began to be actively built up by typical panel apartment buildings. In accordance with the capital class, the normal duration of operating period of such buildings is 125 years. However, the houses that were built according to the standards of half a century ago, now do not meet the

\footnotetext{
${ }^{*}$ Corresponding author: ksenemaltseva@mail.ru
} 
requirements of modern man to the microclimate and comfort. People spend most of their time in rooms with a violation of humidity, temperature, which affects their health. Usually in such buildings there is too cold in winter and hot in summer. Moreover, due to the outdated pipelines there is a threat of sudden disconnection of water and heat supply for an indefinite period.

Do not forget about the economic side of the issue. Often people, without noticing that, pay for heating the streets due to a violation of the building thermal envelope tightness. Obsolete heating devices, as well as the lack of mechanical ventilation systems, do not allow tenants to monitor and set the microclimate parameters according to their preferences. Also, such systems are not flexible and cannot be adapted to the changing Russian climate. Thus, consumers of resources (i.e., residents of apartment buildings) have to pay for the energy that leaks through the holes in the thermal envelope of the building and pipelines, and also for the heat that in the warmest days of the heating season brings them only discomfort.

By the reason of existing contradictions there is an issue of multi-storey panel apartment buildings reconstruction in Russian cities.

\section{International experience in the field of residential buildings renovation}

The problem of apartment buildings reconstruction is relevant not only for Russia. Studying international experience, it was noted that a significant proportion of state and municipal subsidies are accounted for projects for the residential buildings reconstruction including measures to improve the energy efficiency of buildings. For European countries, reducing household consumption of various types of energy and improving the comfort of housing is not only social, environmental and economic tasks, but also political one, since it directly affects the reduction of dependence on imports of natural resources.

In the postwar years in Germany a massive residential development began conditioned by the need to rebuild houses after the bombing as well as resettlement of a large number of refugees. Multi-apartment panel houses, due to the short construction time, perfectly meet the task.

However, at the beginning of the 21st century, buildings no longer meet the requirements of comfort, energy efficiency and housing security. Most of the residents chose to move to new, more comfortable homes, which led to an overpopulation of new districts. In order to attract the population back, it was required not only to improve the external appearance of buildings, but also the economics of their operation. So the government faced a choice between the demolition of physically and functionally obsolete buildings, or their reconstruction. After a technical inspection and evaluation, it was revealed that the first option was economically more expensive. The analytical group calculated that the cost of reconstruction will be about $30 \%$ of the cost of new buildings in the same area. Thus, it was decided to modernize the panel houses in order to increase energy efficiency and reduce the utility bills of citizens, as well as attract residents.

Most of the costs of implementing the program fell on the state, as the main owner. It should be noted that most of the houses that participated in the reconstruction belonged to citizens on a lease basis. Those who have the right of ownership, were granted concessional loans for up to 75 thousand euros at $3 \%$ per annum.

The total cost of renovation amounted to 6.2 billion euro, which is 25 thousand euro per apartment, including 8.5 thousand euro - the cost of measures to improve the energy efficiency of housing.

Within the framework of renovation of buildings the following works were carried out:

- replacement of radiators, installation of energy consumption meters, hot / cold water; 
- insulation of enclosing structures;

- heat insulation of heating pipes;

- replacement of heating boilers

In addition to works aimed at energy saving, measures to provide access to disabled people were taken, the fire safety system was improved, facades were changed, so that the areas of reconstructed houses looked holistically and attractively to residents.

Together with the renovation of buildings, the reform in the supply of heat resources was carried out, which forced supplier companies to modernize plants and distribution networks in order to reduce heat losses. All costs associated with the loss of heat in these areas, lay on the suppliers. The program was implemented within 5 years [2-6].

In France, there are various options for financing and implementing renovation of residential buildings. The housing renewal programs are based on public-private partnerships and contract housing savings, which allow the accumulation of funds on private accounts and receive preferential loans at $4.8 \%$ per annum. There are 4 main options for financing the renovation of residential buildings:

1. The first option is based on the granting of subsidies and benefits to the owners of housing for the renovation of houses, indicating some mandatory measures. Such subsidies can be up to $35 \%$ of the cost of the building.

2. The second option is aimed at creating the conditions for the development of social entrepreneurship and involves providing homeowners with subsidies for renovation at a rate of up to $70 \%$ of the value of the property.

3. The third option is to provide tax incentives to owners during the work on energy efficient housing renovation.

4. The fourth option involves the demolition of dilapidated buildings, followed by the construction of new ones and the compensation of costs by granting subsidies [6].

Slovakia has also met the problem of improving the housing stock. $75 \%$ of residential buildings were built between 1950 and 1990. From the energy efficiency point of view, these buildings belong to classes C-D, while in accordance with modern European requirements, residential buildings must meet the A1 class. Slovakia example is one of the closest to Russia, because during the construction of apartment buildings in the second half of the twentieth century, the same technologies as in the Soviet Union were used.

In Slovakia, homeowners' associations can obtain a soft loan from the State Housing Development Fund to improve the energy efficiency of the apartment building. The minimum amount for obtaining a loan is at least $10 \%$ of the cost of the planned repair. Additional support and guarantee for banks is the activity of specialized agencies that provide guarantees for loans to homeowners associations or specialized management companies for an affordable fee (1-1.5\% of the loan amount).

This practice is also known in Estonia and Lithuania. At the same time, the advisability of guarantee agencies declines in recent years, as financing for renovation is considered by banks as a loan with low risks.

Programs for granting budgetary subsidies are also used to encourage owners to carry out reconstruction. Subsidies can be provided for energy audits and development of project documentation, for reconstruction, for interest payments on a loan.

Scandinavian countries widely use state programs to increase the energy efficiency of residential buildings. In Sweden, the cost of reproduction and maintenance of the house is included in the monthly rent and in the amount can range from 15 to $50 \%$ of the family income.

Issues of reconstruction of the housing stock are relevant not only for Europe. For instance, in Japan subsidies are provided for the reconstruction of residential buildings to meet regulatory requirements for thermal protection, installation of energy-efficient 
household appliances and systems using renewable energy sources. In China, housing savings funds are created through deductions from wages and incomes of employers [6].

Combining the above examples of programs for renovation of apartment buildings, you can see that energy-efficient reconstruction includes a whole range of large-scale tasks:

- Legal (from the decision to carry out renovation to acceptance of the work performed, including design, selection of the general contractor, etc.).

- Research (development of methods for building inspection, technologies for renovation, optimal financing schemes).

- Technical (reconstruction of buildings using specialized technologies, structures, materials and equipment).

- Economic (sources of financing, payback).

- Social (resettlement of densely populated residential areas, improvement of living standards due to increased comfort of housing and the development of internal infrastructure of districts).

- Urban (integrated development of territories)

\section{Problems of implementing energy-efficient renovation in Russia}

Recently, in accordance with the housing legislation of the Russian Federation, the formation of a fund for the reconstruction of apartment buildings can be provided in two ways:

1. On the account of the regional operator. All residents of apartment buildings in the region (with the exception of houses that chose the second method of accumulation) make deductions to the reconstruction fund at a minimum level. Funds from the general account are allocated to the restoration work of houses as needed.

2. On a special account of a particular apartment building. Residents of the apartment building at the general meeting of owners decide to create a special account for the accumulation of funds for reconstruction. Also, residents themselves determine the amount of deductions and, if necessary, can increase or decrease this amount [7].

In the first case, at the expense of the regional operator, only reconstruction works, which are mandatory, can be carried out. The list of obligatory works is established by the local government departments, rather than residents. In most regions, energy efficiency measures are not included in the mandatory list.

Local governments are obliged to pay contributions for the reconstruction of objects of the municipal housing stock. The introduction of additional contributions for the implementation of energy-saving measures will require additional budgetary expenditures, which are generally not available in municipal budgets.

In the second case, the owners determine the list and term of the reconstruction works by themselves at the general meeting. The reconstruction of the common property of a multi-unit residential building is associated with large capital outlays. The average size of the minimum contribution for capital repairs in the country is 6-7 rubles per square meter. In order to save up for reconstruction, without taking into account inflation, it will take from 22 to 44 years. Energy saving measures lead to a significant increase in the cost of reconstruction, and, consequently, an increase in the accumulation period to 74-104 years. Considering the need for current repair of buildings, the accumulation of the necessary amount becomes impossible.

To carry out the reconstruction, including measures to improve energy efficiency, owners could use loans from commercial banks. However, the system of lending for reconstruction in Russia is not developed. Not every region has a bank ready to provide loan funds for repair. Since the system of such lending for financial institutions is new, it is 
considered as highly risky. Rates on loans are about $11 \%$. But there are cases when subsidies from the state were received, covering $9 \%$ of the loan. Such state participation can make reconstruction much more accessible for citizens.

There is another (non-financial) reason for the low motivation of owners to carry out renovations. Residents of an apartment building are usually not specialists in the field of construction, architecture and energy. They do not have enough information and special knowledge that would allow to determine the list of required energy saving works and to assess their economic efficiency. The development of a project of measures to increase the energy efficiency of an apartment building is within the competence of the managing organization. However, for the development of a reconstruction project, a complex and very expensive energy audit of the building is required. The costs of these works cannot be included by the management company in the cost of its management services, and cannot be levied on the owners. Therefore, annual energy efficiency projects are not developed or are formal. Managing organizations are also not interested in investing their own funds and attracting loan funds to finance reconstruction, due to the risk of changing the management method [8].

Thus, the main barriers to the renovation of an apartment building are: Thus, the main barriers to the renovation of an apartment building are:

1. Lack of motivation for local governments and managing organizations to implement measures to improve energy efficiency within the framework of reconstruction of a housing stock.

2. Lack of available credit.

3. Restriction of the list of works on the reconstruction of the apartment building at the legislative level.

\section{Prospects for the implementation of energy-efficient reconstruction in Russia}

As previously shown in Russia there are already several examples of renovation of multiapartment buildings. However, not all regions of our country have experience in implementing such programs. For instance, opportunities to improve energy efficiency of housing can be relevant for the Ekaterinburg, where $25 \%$ of the total housing stock are typical panel apartment buildings.

In the previous chapter, we identified several organizational and legal barriers to the reconstruction of apartment buildings in Russia and in Ekaterinburg, in particular. But is it economically feasible to overcome these obstacles?

To answer this question, we decided to simulate the process of reconstruction of a multi-apartment five-story apartment house series 1-464 in Yekaterinburg, built in the period 1960-1970. Two types of energy efficiency measures, which can be implemented with minimal effort during the reconstruction of the building, were considered:

1. Insulation of exterior walls, replacement of windows with more efficient triple-glazed windows.

2. Insulation of exterior walls, roofs, floors above the basement, replacing windows with more efficient triple-glazed windows.

Expenses for reconstruction in the first case will be about 3.2 million rubles (42 thousand euros), in the second - 5.6 million rubles (73.7 thousand euros).

Return of invested funds is obtained only by reducing the costs of owners for heating.

The payback period for both types of energy efficiency measures is shown in the graph. 


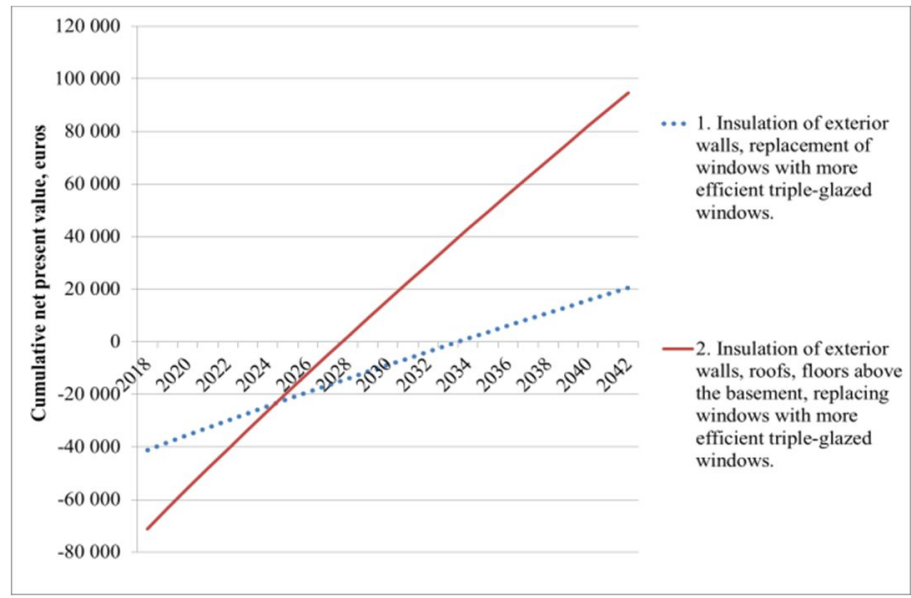

Fig. 1. Determination of the payback period for two types of renovation.

For the second variant of the reconstruction, the payback period is the smallest - about 9.5 years.

Let's consider the possibilities of using alternative sources of financing:

1. Bank loan;

2. Bank loan with state support.

Payback reconstruction funding under these forms are shown in the graph.

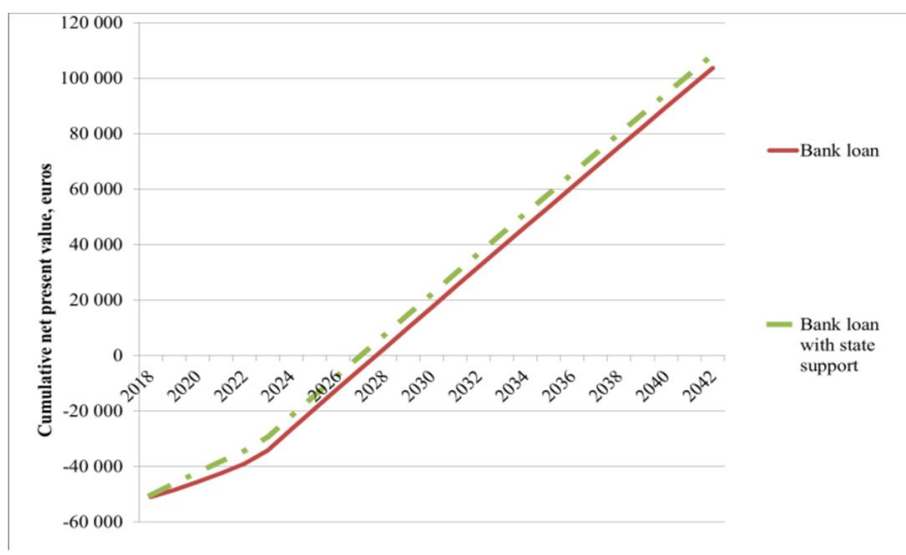

Fig. 2. Determination of the payback period in the case of using alternative sources of funding.

The payback period for capital repairs with the use of a bank loan will be 9 years, state subsidies allow reducing this period to 7.5 years. Note that the rates for loans for the implementation of repair and construction projects in Russia is $11 \%$, while in the European countries about $2-3 \%$, which directly affects the return on investment in reconstruction. However, loans even with high interest rates allow the owners to make their homes comfortable and safe in the short term, followed by the return of the body of the loan and interest due to contributions for reconstruction.

\section{Conclusion}

Using the model of reconstruction of a typical panel apartment building in Ekaterinburg, we showed the payback of minimum energy-saving measures. However, barriers to the 
inclusion of additional energy efficiency improvements in reconstruction programs have been identified. The main problem is the high capital intensity of renovation. But as it was calculated, bank lending programs can make reconstruction for residents more accessible.

The government is interested in improving the energy efficiency of the housing stock, as it relates to the overall economic stability, rational use of energy resources, mitigation of environmental and the solution of some social problems, etc. Accordingly, motivation should be created at the state level and act on all parties involved in the decision-making process.

The government can influence this process at the legislative level by including energy saving and energy efficiency measures in the mandatory list of reconstruction works. Additional funds may also be allocated from the budget for subsidized support to citizens who have decided to improve their living conditions. Funds can be allocated directly to finance works, or to repay interest on a bank loan. Moreover, such a practice of interaction between banks and the government for Russia is not new. Already there are programs in accordance with which when registering a mortgage for new housing, the Housing Development Fund takes a part of the interest on the loan for itself.

On the example of some European countries, another option of state support was considered, when state companies act as guarantors in obtaining residents' loans for renovation. Thus, for banks such loans become less risky, and it becomes possible to lower the interest rate.

From all of the above, it can be concluded that energy conservation measures during the reconstruction can have a real economic effect, but without state support such programs are not available for the majority of the inhabitants of our country.

\section{References}

1. Russian Federation state program "Energy saving and increase of energy efficiency for the period up to 2020" (approved by decree of the Government of thr Russian Federation of Dec.27, 2010 №2446-p)

2. I.S. Cheredina, E.Yu. Rybakova, New Ideas of New Century 1, 402 (2017)

3. D.V. Kovalev, V.G. Chudinova, Architecture and urban planning 13, 4 (2013)

4. Energy-saving renovation of residential buildings in Germany. Available on http://www.nestor.minsk.by/sn/2010/27/02703.html (2018)

5. Reconstruction and modernization (renovation) of residential buildings in East Germany. Useful experience for Russia. Available on http://portalenergo.ru/articles/details/id/121 (2018)

6. G.V. Babenko, M.V. Lukin, Fundamental research 4, 314 (2017)

7. The Housing code of Russian Federation

8. Available on http://www.urbaneconomics.ru/research/analytics/energosberezhenie-priprovedenii-kapitalnogo-remonta-mnogokvartirnyh-domov 